Conclusions Conclusions will be derived in terms of the reach, integrity and acceptability of CSEC. Did CSEC reach the target population? Was CSEC implemented as planned? Is CSEC acceptable to the target population?

\section{CHILD SAFETY EDUCATION COALITION: A MIXED METHODS EVALUATION OF A NATIONAL ALLIANCE}

C Mulvaney*, M Watson, G Errington, C Coupland, D Kendrick Correspondence: CLAHRC NDL University of Nottingham 9 Triumph Road, Nottingham NG7 2GH, UK

10.1136/ip.2010.029215.734

Objective To evaluate a national child injury prevention coalition.

Background The Child Safety Education Coalition (CSEC) is a national alliance set up in 2009 in response to the UK Governments Staying Safe Action Plan which specified actions to be taken to improve the safety of children and young people in England. CSEC, whose members comprise a wide range of practitioners and policy makers in the field of unintentional injuries, will become a national authority on practical child safety education. It will inform and influence policy and practice by encouraging consensus on a range of issues and by collating and sharing information on effective practical safety education. It aims to increase the capacity of safety education provision.

Method A team led by investigators at the University of Nottingham is evaluating CSEC. Evaluation methods are guided by principles outlined by the $\mathrm{WHO}$, namely, participation, capacity building and multiple methods. The team is employing a complex, mixed methods design, including process evaluation, analysis of critical events, case studies and monitoring of child safety education provision. Active participation by evaluators enriches the perspectives, and findings and recommendations are more likely to be accepted as credible.

Results Findings will exam both inward work, that is, processes that build, nurture and maintain the coalition and outward work in terms of achievements. 